\title{
Effectiveness of Psycho-educational Nursing Program on Emotional Distress and Mental Adjustment in Women with Breast Cancer
}

\author{
*Safa Mohammed,** Sayeda Ahmed,*** Maaly Ebraheem,**** Mawaheb Mahmoud \\ * Psychiatric and Mental Health Nursing Department- Faculty of Nursing- BeniSuief University \\ ** Psychiatric Health Nursing -Faculty of Nursing-Cairo University \\ *** Psychiatric Health Nursing-Faculty of Nursing - EL Menoufya University \\ ***** Psychiatric Health Nursing- Faculty of Nursing-Benha University
}

\begin{abstract}
Background: Emotional distress in Breast cancer patients may interfere with the ability to cope effectively with breast cancer, its physical symptoms and its treatment. This in turn causes significant increase in psychiatric morbidity leading to poor adjustment in the patients. This study aimed to evaluate the effectiveness of the psycho-educational program on emotional distress and mental adjustment among women with Breast Cancer. A quasi-experimental design (one group prelposttest) was used to achieve the aim of the study. A convenient sample of 50 adult women diagnosed with breast cancer. This study was conducted at the outpatient department of the clinical oncology center at the Nasser Institute Hospital. Data were collected by using three tools: structured interview questionnaire sheet, Hospital Anxiety and Depression Scale (HADS), and Mini-Mental Adjustment to Cancer Scale (Mini-MAC). Results: The result revealed that there was reduction in the mean score of anxiety and depression of the studied subjects post program than before with highly statistically significant differences. There was also a statistically significant increase in the total mean scores of all mental adjustment subscales among the studied women after participation in the psycho-educational program than before. Conclusion: The psycho-educational intervention program was the key element in reducing emotional distress and improving mental adjustment for women with breast cancer. The study recommended generalization of psycho-educational intervention programs for all patients with breast cancer.
\end{abstract}

Key words: Breast Cancer, Emotional Distress, Mental Adjustment, Psycho-education.

Introduction

Despite significant improvements in the treatment of cancer, cancer is still the most dreadful disease that have a deep psychological effect on people. From the pre diagnosis to the terminal stage, cancer causes considerable stress and impairs adjustment of the patient (Dastan \& Buzlu, 2012). In breast cancer, the degree of psychological response is closely related to emotions about breast. In our country, as in other countries, breast of a woman symbolizes femininity, sexuality, esthetic appearance, feeding the baby, love and maternity. For this reason, after breast cancer, women usually experience severe psychological problems such as concern about impaired body image, reduced self-esteem, feeling of losing their femininity and decrease in sexual functions, anxiety, depression, desperation, guilt and shame, fear of a relapse, isolation and fear of death (Lewis et al, 2012). 
The impact of a breast cancer diagnosis and its subsequent treatment is a major turning point in women's lives. The diagnosis of breast cancer should not only include physical condition, but also social and psychological condition. This is due to the importance of breast in the women's body image, sexuality and motherhood. When a woman is informed that she has breast cancer, she is faced with physiological imbalance, psychosocial distress, uncertainties, social isolation, and sudden termination of her customary lifestyle. These women are most vulnerable to emotional distress immediately after diagnosis, and that distress continues for two to three months into the illness (Ohaeri et al., 2012).

Women in this situation have to deal and cope with all of these problems to adjust to their diagnosis, and they must deal with the loss of breast tissue, any side effects of adjuvant therapy, and generally with their new life circumstances. The ways that patients attempt to cope with their disease and the effects of treatment are central in determining the course of psychological distress and adjustment which enhances quality of life and decrease distress in breast cancer patients. The emotional distress may interfere with the adjustment process and alter such physiological parameters as immune functions and the course of the disease. Adjustment is an ongoing process, determined to a large extent by ways of coping with the disease and treatment (Artherholt \& Ann, 2012).

One of the most effective psychosocial approaches to cancer patients is psychoeducation. Psycho-education is a specialized education that consists of educational and psychosocial endeavors with an aim to create behavior change in patients. Planned psychoeducational programs assist patients and their families to cope with and adapt to the difficulties associated with the disease, enable them to develop their problem solving skills and increase their quality of life (Dastan\&Buzlu, 2012).

\section{Significance of the study:}

The incidence rates of breast cancer in Egypt, is the most common cancer among Egyptian women, incidence rates representing (less than 40 per 100,000) $32.0 \%$ of total cancer cases. This results presents the incidence rates of cancer in Egypt in 2008-2011 based upon data of the National Cancer Registry Program in Egypt with an estimated incidence of the disease up to 2050( Ibrahim et al., 2014). In addition to, $20 \%-30 \%$ of breast cancer patients suffer from psychiatric morbidity, such as anxiety and/or depression. Heightened anxiety and depression are not only limited to the active treatment period, but may persist for months or even years following successful treatment (Midtgaard et al., 2011). Based on these results, the present study focus on the psychological reaction, adaptation and recovery as important factors for women with breast cancer. The study will be of great importance to the nursing profession, for improving nursing practice in the clinical area by stressing the importance of dealing with women with breast cancer not only physically, but also psychologically. For research, it will add a new trend in understanding the importance of psychological aspect and its effect on the health status of breast cancer patients. Therefore, the need to plan to overcome this problem among women with breast cancer is crucial in Egypt.

\section{Aims of the study:}

Investigate the effectiveness of psychoeducational program on emotional distress and mental adjustment in women with Breast Cancer. 


\section{Specific objectives of this study}

1- Assess the level of anxiety and depression in women with breast cancer.

2- Assess mental adjustment in women with breast cancer.

3- Implement and evaluate the effectiveness of psycho-educational interventions on emotional distress and mental adjustment in women with Breast Cancer.

\section{Research hypotheses}

Women with breast cancer who will attend a psycho-educational program will have a reduction of mean score of (anxiety and depression), increase in the mean score of mental adjustment after the program than before the program.

\section{Subject and methods:}

\section{Research Design:}

A quasi-experimental design (one group prelposttest) was used in the current study to achieve the aim of the study.

\section{Setting}

The study was conducted at the outpatient department of the clinical oncology center at the Nasser Institute Hospital.

\section{Subjects}

A convenient sample of 50 adult women diagnosed with breast cancer who were involved in treatment and follow up in the outpatient department of the clinical oncology center at the Nasser Institute Hospital who fulfill the following inclusion and exclusion criteria

\section{Inclusion criteria:}

1) Aged over 18 years

2) Having a score of $>20$ on the Hospital Anxiety and Depression Scale

3) Ability to communicate.

4) Willing to participate in the study.

\section{Exclusion criteria}

1) Diagnosed with other form of cancer than breast cancer.

2) Have a history of major mental disorder or other medical condition.

\section{Tools for data collection:}

The data was collected through the following tools:

Tool (1): A structured interview questionnaire sheet

The structured interview questionnaire sheet was developed by the researcher based on scientific review of literatures and under guidance of supervisors. It was divided into two parts:

- First part: this part includes items related to Socio-demographic characteristics of the patients as age, marital status, and occupation. etc.

- Second part: this part includes items related to Clinical characteristics of the patients as time since diagnosis, and treatment adopted by the participants etc.

Tool (2): The Hospital Anxiety and Depression Scale (HADS)):

It was developed by Zigmond and Snaith (1983) to detect the presence and 
severity of anxiety and depressive symptoms in people with physical health problem. It was translated into Arabic and tested for its validity and reliability by the research. It consists of a 14 items. It was divided into two subscale anxiety and depression subscale both containing seven items. The scoring system was categorized as follows:

* 'No emotional distress' (score below 8)

* 'Mild emotional distress'(score 810)

* 'Moderate emotional distress ' (score 11-15)

* 'Severe emotional distress (score 16 or higher)

Tool (3): The Mini-Mental Adjustment to Cancer Scale (Mini-MAC)

This scale was developed by Watson et al., (1994)as a method to measure cancer patients' adjustment to the diagnosis and treatment. The Mini-MAC is a Likert type scale with four response options: (1) does not apply to me at all (2) does not apply to me (3) applies to me (4) applies to me very much... The scale consists of 29 items. in the form of 5 sub-dimensions as follows:

- Helpless-Hopeless, e.g. "I feel completely at a loss about what to do" (8 items)

- Cognitive Avoidance, e.g. "I distract myself when thoughts about my illness came into my head" (4 items)

- Fighting Spirit, e.g. "I try to fight the illness" (4 items)

- Anxious Preoccupation, e.g. "I worry about the cancer returning or getting worse" (8 items)
- Fatalism, e.g. "I've had a good life; what's left is a bonus" (5 items). follows:

The scoring system was categorized as

* Poor adjustment to cancer diagnosis and treatment: Less than score 47 mean

* Mild adjustment to cancer diagnosis and treatment: Score from 47 to 73 mean

* Moderate adjustment to cancer diagnosis and treatment: Score from 74 to 101 mean

* High adjustment to cancer diagnosis and treatment: Score from 102 to 116 mean

\section{II-Methods}

\section{Field work:-}

The present study was conducted in four phases:

\section{Preparatory Phase:-}

This phase included reviewing of relevant literature and different studies related to the topic of research, using textbooks, articles, magazines, periodicals, and internet search was done to get a clear picture of all aspects related to the research topic to design the program, Then the tools were translated into the Arabic language by language experts and back translated to ensure its accuracy

\section{Content validity and reliability}

Content validity of tools was done by a Jury of 5 experts of psychiatric mental health nursing field and medical psychiatric staff. 
Test re-test reliability was done, $r=0.77$ for the depression subscale and 0.81 for the anxiety subscale, $\mathrm{r}=0$. 88for self esteem, while $r=0.79$ for Mini-MAC scale.

\section{Administrative Design:}

An official approval to carry out the study was obtained from the Faculty of Nursing / Benha University to the director of the Nasser Institute Hospital after revision of the study procedure the protocol, tools, and the booklet. The purpose and the nature of the study were explained to the hospital's staff to obtain their cooperation to conduct the study.

\section{Ethical considerations:}

The subjects who agreed to participate in the study were assured about confidentiality and anonymity of the study. They were informed about their right to withdraw from the study at any time.

\section{Pilot study:}

Before starting data collection a pilot study was conducted on 5 patients to assess the clarity and applicability of the study tools, and identify the time needed to fill each tool as well as to find out any problems that might interfere with data collection, then the final format was developed under the guidance of supervisors. These patients were excluded later from the actual study. Necessary modifications were done (e.g; change Arabic translation of some questions to another word to be more understandable for the patient).

\section{Data collection procedure:}

The current study was carried out in three phases, namely preparatory, implementation, and evaluation phases.

\section{The preparatory phases:-}

An extensive literature related to the study area was done including electronic dissertation, available books, articles, doctoral dissertation, research and peer interaction, and idea from external sources and periodicals. A review of literature to formulate knowledge base relevant to the study area was also done.

The researcher plan articulates for describing the aim of the study to participants, the actual collection of data and recording information. A guide booklet was prepared by the research, reviewed by a jury.

\section{The implementation phase:-}

The researcher applied the implementation phase according to the following steps:

All subjects who were supposed to be meeting the inclusion criteria were included in the study, then divided into (10) groups, every group consisted of (5) patients, every group attended $(8)$ nursing intervention session within two dayslweek .The study was carried out in the period started from (1/April-2016 to 30/ july 2016).

The implementation of the study passed into three phases (pre assessment phase, implementation phase, and post assessment phase).

\section{Pre assessment phase:-}

A comfortable, private place was chosen for the interviewers. Orientation was done about the purpose of the study and content of the study. Each women was individually interviewed where pre assessment was done using structured interviewing questionnaire, emotional distress scale and mental adjustment scale. 


\section{Implementation phase:-}

This study hypothesized The women who participate in the nursing intervention program will have lower mean score of emotional distress and higher mean score mental adjustment post program than before program . This program has a general objective and divided into (8 )sessions. Each session lasted for 90 minutes and has a set of specific objective. This was achieved through several teaching methods as brain storming, lecture, group discussion; role playing, data show, picture, posters and booklet were used as media. At the end of each session summary, feedback, further clarification was done for vague items and homework activity for the following session.

\section{The sessions of intervention were:}

Session 1: Program orientation and expectation

Time required for session: 90 minute

\section{Specific objectives:}

At the end of this session each patient will be able to:

- Establish a trustful therapeutic relationship between patients and researcher.

- Illustrate the importance of psychoeducational program and its purpose by giving a simple idea about its contents.

- Describe schedule of the program.

\section{Contents:}

- The researcher greeting and introducing herself to the group and so each participant introduce herself to the group, this objective creates a kind of familiarity and acceptance and mutual trust between the researcher and the group.

- Researcher presented the objectives of the program and its significance for the patients to participate and cooperate with the assurance that what is known during sessions of conversations and the discussion is confidential by the researcher.

- The patients asked to attend the program at the predetermined schedule time to participate in the implementation of the program.

- Encourage patients to ask questions for the researcher to clarify all important aspects.

- Ask questions for patients to make sure they have acquired the knowledge required.

- Listen to their opinions and criticism.

- Fill questionnaires required.

- Provide participants with a personal guide to overcoming anxiety and depression gives the opportunity for the patient reference at any time.

\section{Session 2: Overview of breast cancer.}

Time required for session: 90 minute.

\section{Specific objectives:}

At the end of this session each patient will be able to:

Gain some scientific facts and information about breast cancer, treatment 
and side effects of treatment and how to deal with these effects.

\section{Content}

- Giving a clear picture of breast cancer (definition-causes-symptoms-treatment methods-how to cope with side effects of treatment).

- Clarify the importance of both healthy nutrition and physical activity

- Adding necessary information as needed.

- Correct some wrong concepts in patient and promote correct concepts.

Session 3: Emotional distress and its relationship to breast cancer.

Time required for session:90 minute.

\section{Specific objectives:}

At the end of this session each patient will be able to:

Explain emotional distress

Identify symptoms of emotional disorders associated with breast cancer

Understand the strong relationship between emotional distress and body.

\section{Content}

- Initial discussion about breast cancer consequences of emotional and physical status.

- More information about emotional disorders (depression -anxiety).
- The relationship between emotional distress and body.

- Open discussion about patients (impact - feeling - symptoms of depression and anxiety).

Session 4: feelings and emotions in everyday situations.

Time required for session: 90 minute.

\section{Specific objectives:}

At the end of this session each patient will be able to:

- Identify feelings and emotions experienced by the participants in their dealings with their lives.

- Avoid negative feelings and emotions to everyday situations.

- Replace negative feelings and emotions with positive ones.

\section{Contents:}

- Identifying feelings and emotions experienced by the participants in their dealings with their lives.

- Discussion about the nature of life situations and result in positive or negative feelings and emotions,

- Evaluate those feelings and emotions in an attempt to train patients to recognize the negative and replaced with positive ones.

\section{technique}

Session 5: Training on relaxation

Time required for session:90 minute.

\section{Specific objectives:}


At the end of this session each patient will be able to:

- Understand the definition of relaxation.

- Explain the difference between tension and relaxation.

- Acquire skills to deal with anxiety through training on relaxation techniques

\section{Contents:}

- The definition of relaxation

- The differences between tension and relaxation

- The benefits of relaxation.

- View the relaxation training (deep breathing - muscle relaxation exercises)

Session 6: Developing skills using Cognitive Restructureto overcome emotional disorders(1)

Time required for session: 90 minute.

\section{Specific objectives:-}

At the end of this session each patient will be able to

- Acquire skills to deal with depression and anxiety through training on

* The Technique of identifying automatic Ideas and correcting them

* Self - Monologue technique

\section{Contents:}

- Explaining technique of identifying automatic ideas and correcting them
- Training on the technique of detain identifying automatic ideas and correcting them and applying it.

- Explain Self - Monologue technique

- Training on self - monologue technique and applying it.

Session 7: Developing skills using Cognitive Restructure to overcome emotional disorders (2).

Time required for session: 90 minute.

\section{Specific objective:-}

At the end of this session each patient will be able to:

- Acquire skills to deal with depression and anxiety through training on

Idea's Termination Technique.

Self-monitoring

\section{Contents:}

- Explain ideas termination technique

- Training on the ideas termination technique and applying it.

- Explain self-monitoring technique

- Training on self-monitoring technique and applying it.

Session 8: Developing a personal plan for managing depression and anxiety related problems in the future

Time required for session:90 minute.

Specific objective:- 
At the end of this session each patient with breast cancer will be able to:

- Use problem-solving strategy for application in the reality of everyday life in new situations or when faced with future problems.

\section{Contents:}

- Explaining the problem solving technique.

- Explaining the stages to be followed while solving the problem

\section{The evaluating phase:}

During this phase, the participant was encouraged to ask any questions or demand clarifications she needed and the post- test was given to them( emotional distress scale, and mental adjustment scale ).

\section{IV- Statistical analysis:-}

Data was coded and transformed into specially designed form to be suitable for computer entry process. Data was entered and analyzed by using SPSS (Statistical Package for Social Science) statistical package version 16. Graphics were done using Excel program. Qualitative data were presented in the form of frequency distribution tables, number and percentage. It was analyzed by chi-square $\left(\chi^{2}\right)$ test. However, if an expected value of any cell in the table was less than 5, Fisher Exact test was used. Qualitative data were expressed as mean \pm standard deviation where paired $\mathrm{t}$ test was used. Correlation between the variables was evaluated using Pearson's correlation coefficient (r). Significance was adopted at $p<0.05$ for interpretation of results of tests of significance.

\section{Limitation of the study:-}

No limitations were found.

\section{Results:}

Table 1: represents the distribution of the studied subjects according to their personal characteristics. This table shows that, the studied sample consists of 50 women with a mean age of $52 \pm 13.3$, more than three quarter of them $(76 \%)$ are between $40-60$ years. The majority of the studied women $(80 \%)$ is married, and a minority of them $(6 \%)$ is single. Regarding occupation, the majority of the studied women $(86 \%)$ are not working. Concerning their residence, more than half of the subjects $(56.0 \%)$ live in rural areas and nearly half of them $(46.0 \%)$ have intermediate education.

Table 2: reveals that, there is a highly significant reduction in the level of anxiety post intervention program than pre intervention program where before the program more than half $(52 \%)$ of the studied subject have moderate anxiety and near to one third of the studied subject $(32 \%)$ have severe anxiety reduced to $(15 \%)$ for moderate anxiety and (8\%) for severe anxiety respectively. This table also shows that, there is a highly significant reduction in the level of depression post intervention program than pre-intervention program where before the program near to half (48\%) of the studied subject have severe depression and more than one third of the studied subject (34\%) have moderate depression reduced to $(14 \%)$ for severe depression and (24\%) for moderate depression respectively.

Figure 1: shows that, there is statistically significant reduction in the total mean scores of the studied women of helplessness-hopelessness and anxious preoccupation while an increase in the mean score of cognitive avoidance, fighting spirit, and fatalism post program implementation than before program implementation at $\mathrm{p}<$ 0.001 . 
Effectiveness of Psycho-educational Nursing Program on Emotional Distress and Mental Adjustment in Women with Breast Cancer

Table 3: shows the correlation between mini-mental adjustment to cancer with anxiety and depression at prelpost program implementation. The table reveals that, there is no significant correlation between minimental adjustment to cancer with anxiety and depression at pre program implementation while at post program implementation there is negative significant correlation between mini-mental adjustment to cancer with anxiety and depression

Table (1): Socio-demographic characteristics of the studied subjects $(n=50)$

\begin{tabular}{|c|c|c|}
\hline Items & $\mathbf{N}$ & $\%$ \\
\hline \multicolumn{3}{|l|}{ Age } \\
\hline$<40$ & 5 & 10.0 \\
\hline $40-60$ & 38 & 76.0 \\
\hline$>60$ & 7 & 14.0 \\
\hline \multicolumn{3}{|c|}{ Mean \pm SD: $52 \pm 13.3$} \\
\hline \multicolumn{3}{|l|}{ Marital status } \\
\hline Single & 3 & 6.0 \\
\hline Married & 40 & 80.0 \\
\hline Widow & 7 & 14.0 \\
\hline \multicolumn{3}{|l|}{ Occupation } \\
\hline Working & 7 & 14.0 \\
\hline Not working & 43 & 86.0 \\
\hline \multicolumn{3}{|l|}{ Residence } \\
\hline - Urban & 22 & 44.0 \\
\hline - Rural & 28 & 56.0 \\
\hline \multicolumn{3}{|l|}{ Education } \\
\hline - $\quad$ Read and write & 4 & 4.0 \\
\hline - Basic & 9 & 18.0 \\
\hline - Intermediate & 23 & 46.0 \\
\hline - High & 14 & 28.0 \\
\hline
\end{tabular}

Table 2: Distribution of the level of anxiety and depression Pre $\backslash$ Post the psychoeducational program $(\mathbf{n}=\mathbf{5 0})$

\begin{tabular}{|c|c|c|c|c|c|c|c|c|c|c|}
\hline & \multicolumn{4}{|c|}{ HADS (A)score } & \multirow{3}{*}{$\begin{array}{l}\text { Test } P \text { - } \\
\text { value }\end{array}$} & \multicolumn{4}{|c|}{ HADS(D)score } & \multirow{3}{*}{ Test P-value } \\
\hline & \multicolumn{2}{|c|}{ Pre test } & \multicolumn{2}{|c|}{ Post test } & & \multicolumn{2}{|c|}{ Pre test } & \multicolumn{2}{|c|}{ Post test } & \\
\hline & No & $\%$ & No & $\%$ & & No & $\%$ & No & $\%$ & \\
\hline No Case & 0 & $0 \%$ & 7 & $14.0 \%$ & $\chi 2=25.15$ & 0 & $0 \%$ & 10 & $20.0 \%$ & $\chi 2=24.98$ \\
\hline Mild & 8 & $16.0 \%$ & 24 & $48.0 \%$ & $\mathbf{P}<0.001 * *$ & 9 & $18.0 \%$ & 21 & $42.0 \%$ & $\mathbf{P}<0.001 * *$ \\
\hline Moderate & 26 & $52.0 \%$ & 15 & $30.0 \%$ & & 17 & $34.0 \%$ & 12 & $24.0 \%$ & \\
\hline Severe & 16 & $32.0 \%$ & 4 & $8.0 \%$ & & 24 & $48.0 \%$ & 7 & $14.0 \%$ & \\
\hline
\end{tabular}


Figure 1: Comparison between the total mean scores of the 5 domains of Mini-Mental Adjustment Scale to Cancer pre Ipost the psycho-education program implementation

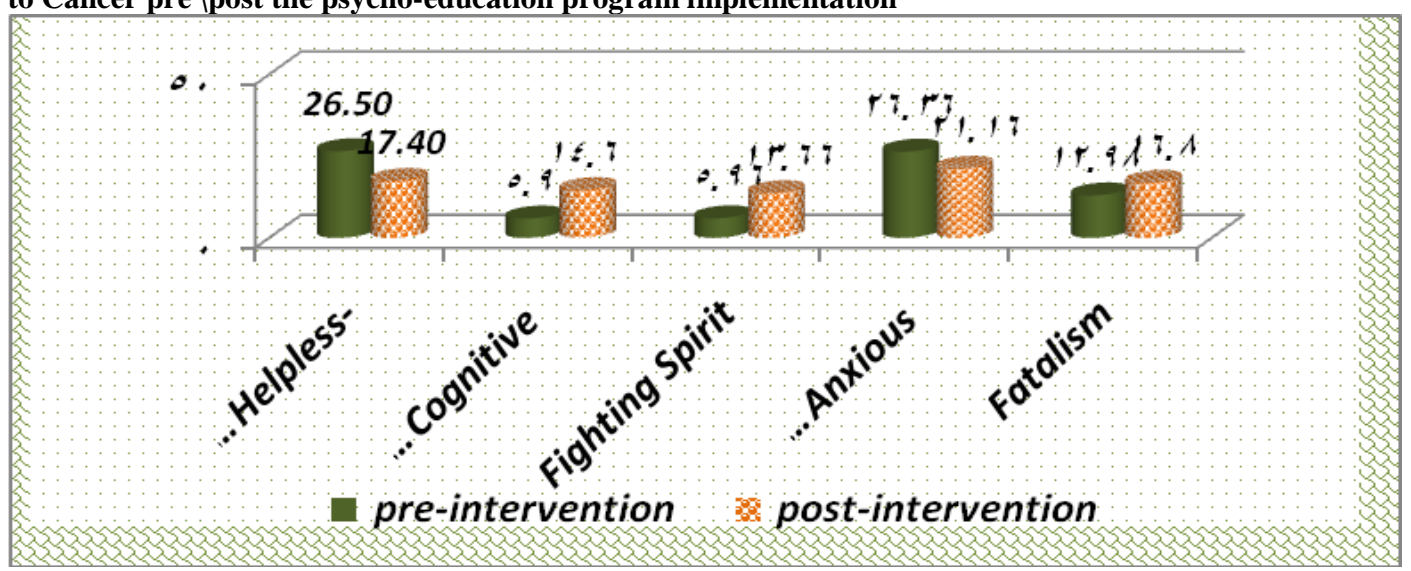

Table (3): Correlations between total mini-mental adjustment to cancer with total anxietyand depression at pre $\backslash$ post psycho-education program implementation $(\mathbf{n}=50)$

\begin{tabular}{|c|c|c|c|c|c|c|c|c|}
\hline \multirow[t]{3}{*}{ Variable } & \multicolumn{4}{|c|}{ Pre-intervention } & \multicolumn{4}{|c|}{ Post-intervention } \\
\hline & \multicolumn{2}{|c|}{ Anxiety } & \multicolumn{2}{|c|}{ Depression } & \multicolumn{2}{|c|}{ Anxiety } & \multicolumn{2}{|c|}{ Depression } \\
\hline & $r$ & $\begin{array}{c}P \\
\text { value }\end{array}$ & $r$ & $\begin{array}{c}P \\
\text { value }\end{array}$ & $r$ & $P$ value & $r$ & $P$ value \\
\hline $\begin{array}{l}\text { Total } \\
\text { mental } \\
\text { adjustment }\end{array}$ & $\begin{array}{c}- \\
0.266\end{array}$ & .064 & $\begin{array}{c}- \\
.418\end{array}$ & .003 & $\begin{array}{c}- \\
.480\end{array}$ & $<0.001 * *$ & $\begin{array}{c}- \\
.495\end{array}$ & $<0.001 * *$ \\
\hline
\end{tabular}

* *Highly statistically significant

Discussion:

Readjusting to life after breast cancer is likely to be challenging for women. Difficulties in adjustment are typically associated with reports of depression, feelings of hopelessness, fatigue, anxiety, and sometimes suicidal ideation. A multitude of related problems, including maladaptive coping behaviors, greater disability, poorer social functioning, and loss of functional independence, may result from difficulties in psychological adjustment. Therefore, early recognition of the emotional requirements by the health professional involved in the treatment process, not only decrease the cost burden of cancer treatment, but at the same time improve quality of life.

This result of the present study revealed that more than half of the study subjects age ranged between >40-60 years old with a mean (52 \pm 13.3 ). This could be due to hormonal changes or be due to level of knowledge about breast cancer, specifically older patient had less knowledge about breast cancer and its treatment. This was consistent with, a study done by Jassim \& Whitford (2013) in Bahrain, which measure the quality of life of Bahraini women with breast cancer, showed that the mean age of participants was $(52.2 \pm 11.1)$. At the same time, 
this result also was in agreement with another study done by Faria (2010) who, considered that breast Cancer to be rare prior to the age of 35 . Therefore, this similarity in mean age in that previous studies accordance to WHO (2011) statistics indicated that a diagnosis of breast cancer increases with age. Age can be considered as a crucial precursor of patients' distress based mainly on deficits in knowledge, which then leads to lack of confidence in coping efficacy and distress. In contrast, a study carried out by Sharif, et al. (2010), who emphasized that, most women diagnosed with breast cancer are between 25 to 40 years of age and this rate drop after the age of 44 .

As regards to educational status, it was found that about half of the participants had an intermediate level of education, that facilitated easy understanding, acceptance and interaction with the psycho-educational intervention program, this was reflected immediately post intervention. As they had an insisting desire to gain knowledge and learn how to cope. This is beneficial according to what is stated by Mahmoud et al. (2005), who reported that the educational level is considered a personal resource that influences the individual's ability to cope. That result is in accordance to the study done by Ögce and Özkan (2008) which showed the same results, that half of the study sample had intermediate level education and lower.

With regard to residence, the result of the current study revealed that, more than half of the studied women live in rural areas. This could be due to women in rural area have a greater desire to gain heath related information about cancer breast. This finding is consistent with Santre, Rathod, \& Maidapwad (2014), who found that, more than half of the participants were from rural backgrounds that have come to this tertiary care center for specialty treatment as rural women desire greater health-related information about their breast cancer.

Regarding marital status, results of the present study showed that more than three quarters of the subjects were married. This result is in line with Alhamss (2014) who reported that, married women were the most (three fourths) of clients and more likely to cope compared with divorced, or widowed. Concerning employment, the majority of the studied subjects was not working; this might be because the perceived burden of the continuation of the work and the frequent hospital visit leading to poor work performance, frequent absenteeism and fear of removal from the employment place all leads to increased emotional distress in patients. This could also be explained as the highest percentage of women was house wives. That result is in accordance to the study done by Alhamss (2014) who showed the same results, that a majority of the study sample women with breast cancer was not working.

In this study, the studied women were found to have increased emotional distress on the level of anxiety and depression as the studied women experienced a significant level of anxiety where more than half of the sample reported moderate anxiety and near to one third experienced severe level of anxiety, while about half of the sample experienced severe level of depression pre intervention program. This can be attributed to the impact of more extensive surgery or the side effects of treatment, anxiety regarding the intervention procedures, self analysis of the treatment modalities from the knowledge which patients gather from various sources and finally the thought regarding the outcome of the treatment all this leads to distress. These procedures produce limitations in activity causing distress or may be due to poor coping skills of the patient. Also, the lack of knowledge about the disease and its treatment may be considered as one of the causes of higher anxiety and depression in this study. This finding is in an agreement with Sharma\& Zhang. (2015), who stated that, nearly half of women with early breast cancer had depression, anxiety or both in the year after diagnosis.

Regarding the effect of the psycho-education program on emotional distress of the studied women, results showed a statistically significant decrease in the level of emotional distress among the studied women after participation in the psycho-educational program. This can be explained that, the psycho-education program help the women to identify conditions or situations that affect emotional status and to analyze thoughts and beliefs about them, as being rational or irrational. Then, replace these with accurate, rational, constructive thoughts. Also, it helps the women to accept themselves. This leads to experiencing positive emotions such as hope, 


\section{Safa Mohamed, Sayeda Ahmed, Maaly Ebraheem \& Mawaheb Mahmoud}

positive overvaluation of the disease and finally to constructive adaptation to the state of being ill.

The results of the current study revealed that highly statistically significant differences were found in all the mental adjustment subscales among the studied women at post the psychoeducational program than before. The result revealed that the psycho-educational intervention was effective in improving mental adjustment to cancer in women diagnosed with (and treated for) breast cancer, causing a specific and significant reduction in anxious preoccupation and helplessness/hopelessness while a significant increasing was observed on the other parameters explored with Mini-MAC, such as fighting spirit, cognitive avoidance and fatalism. This can be explained that, since the mental adjustment of the studied women has been enhanced by instructing the ways of overcoming stress, so that the studied women who have learned how to deal with and overcome stressful circumstances, consequently had improved their mental adjustment and have developed their compatibility of solving their problems. Added to that, women have a lot of misconceptions about breast cancer, such as cancer is incurable, cancer means death, etc. These findings are in agreement with Dastan \& Buzlu (2014) who revealed that, psycho-education was shown to cause positive changes in levels of mental adjustment to cancer in breast cancer patients. However, in an early structured psychoeducational intervention carried out byCapozzo et al. (2010) reported that, that a significant reduction only in anxious preoccupation was observed in treated patients, whereas the other coping strategies identified by the Mini-Mental Adjustment to Cancer scale were not significant.

As for the correlation between mini-mental adjustment, HADS (anxiety and depression),the results of the current study demonstrated that there is negative correlation between mini-mental adjustment to cancer with anxiety and depression. The current study found that, higher levels of fighting spirit, fatalism, cognitive avoidance and lower levels of hopelessness/ helplessness, anxious preoccupation were associated with lower levels of anxiety, depression, this indicates that as the higher adjustment to the diseasel, the lower the probability of occurrence of mental disorders (anxiety, depression) over the course of the disease and during treatment.
This finding generally supports the results of previous studies that have used the MAC scale. A study was done by Johansson, Rydén \& Finizia (2011), who reported that patients using helplesshopeless and anxious preoccupation responses reported more anxiety and depression. Added to that a study done by Seok et al. (2013), in which a correlation between anxious-preoccupation with depressive symptoms in breast cancer patients was reported. However, this finding is in contrast with Okano et al. (2011), who revealed that, emotional distress according to the DSM-III-R criteria was not correlated with fighting spirit and helplessness/hopelessness, in particular, has been consistently suggested to be strongly correlated with anxiety and depression in many studies.

\section{Conclusion:}

The psycho-educational intervention program has a greater effect in reducing emotional distress for women with breast cancer improve their mental adjustment.

\section{Recommendations:}

The current study recommended the need for stress management training program should be given to patients with breast cancer to relieve their psychological problems and enhance their mental adjustment.

\section{References:}

Alhamss, A. (2014): Health promotion program among breast cancer patients receiving chemotherapy in south governorates in Gaza. Un published, Doctorate thesis, faculty of nursing, Cairo university. Egypt.p72.

Artherholt, S., \&ann, J. (2012): Psychosocial care in cancer. Curr Psychiatry Rep.2012;14(1):23-9.

Capozzo et al. (2010):An Early Structured Psycho educational Intervention in Patients With Breast Cancer Cancer Nursing TM, Vol. 33, No. 3, Lippincott Williams \& Wilkins.

Dastan, N., \&Buzlu, S. (2014): Psycho education Intervention to Improve Adjustment to Cancer among Turkish Stage I-II Breast Cancer Patients: A Randomized Controlled Trial. 
Asian Pacific J Cancer Prev, 13 (10), 53135318.

Faria, L. (2010): As práticas do cuidarnaoncologia: a experiência da fisioterapiaempacientes com câncer de mama. HistCiencSaude- Manguinhos; 17(1):69-87.

Lewis, P., Sheng, M., \& Rhodes, M., et al. (2012): Psychosocial concerns of young African American breast cancer survivors. J PsychosocOncol, 30, 168-84.

Ibrahim, A., Khaled, H., \& Mikhail, N. et al. (2014):Cancer Incidence in Egypt: Results of the NationalPopulation-Based Cancer Registry Program. Journal of Cancer Epidemiology, Article ID 437971, 18 pages at: http://dx.doi.org/10.1155/2014/437971

MAHMOUD, M., SOBH, A., EL-HABASHI, F. \& GHONEIM, A.(2005): Interferon therapy in hemdialysis patients with chronic hepatitis $\mathrm{C}$ : Study of tolerance, efficacy and posttransplantation course. Nephron Clinical Practice, 100 (2): 133-139.

Midtgaard, J., $\quad$ Stage, M., \&Møller, T. et al. (2011):Exercise may reduce depression but not anxiety in self-referred cancer patients undergoing chemotherapy. Post-hoc analysis of data from the 'Body \& Cancer' trial. Volume 50; Pages 660-669.

Jassim, G., \&Whitford, D. (2013):Quality of life of Bahraini women with breast cancer: a cross sectional study. BMC Cancer; 13: 212.

Johansson, M., Rydén, A., \& Finizia, C. (2011):Mental adjustment to cancer and its relation to anxiety, depression, HRQL and survival in patients with laryngeal cancer - A longitudinal study. BMC Cancer;11:283

Ögce, F., \&Özkan, S. (2008): Changes in Functional Status and Physical and Psychological Symptoms in Women Receiving Chemotherapy for Breast Cancer. Asian Pacific Journal of Cancer Prevention, Vol 9, 449-452
Ohaeri, B., Ofi, A., \& Campbell, O. (2012): Relationship of knowledge of psychosocial issues about cancer with psychic distress and adjustment among breast cancer clinic attendees in a Nigerian teaching hospital. Psycho-Oncology, 21, 419-26.

Okano, Y., Okamura, H., \& Watanab, T., et al. (2011): Mental adjustment to first recurrence and correlated factors in patients with breast cancer. Breast Cancer Research and Treatment 67: 255-262.

Rosenberg, M. (1965): Society and the adolescent self-image. Princeton, NJ: Princeton University Press. Death.

Santre, M., Rathod, J., \& Maidapwad, S. (2014): Prevalence of Emotional Distress in Cancer Patients. IOSR Journal of Dental and Medical Sciences (IOSR-JDMS), Volume 13, Issue 6 Ver. V (Jun. 2014), PP 09-14.

Sebastián, J., Manos, D., Bueno, M., \&Mateos, N. (2008): BODY IMAGE AND SELF-ESTEEM IN WOMEN WITH BREAST CANCER PARTICIPATING IN A PSYCHOSOCIAL INTERVENTION PROGRAM. Psychology in Spain, Vol. 12. No 1, 13-25.

Seok, J., Choi, W., \& Lee, Y., et a;. (2013): Relationship between Negative Mental Adjustment to Cancer and Distress in Thyroid Cancer Patients . Volume 54 Number 3. Available at: http://www.eymj.org.

Sharma, A., \& Zhang, J. (2015): Depression And Its Predictors Among Breast Cancer Patients In Nepal ASEAN Journal of Psychiatry, Vol. 16 (1).

SHARIF, F., ABSHORSHORI, N., TAHMASEBI, S., et al.(2010): The effect of peer-led education on the life quality of mastectomy patients referred to breast cancerclinics in Shiraz, Iran. Health Quality of Life Outcomes, 2 (6); 8: 7420.

Watson, M., Law, M., \& DOS Santos, M., et al,. (1994): The Mini-MAC: Further development of the mental adjustment to cancer scale. J PsychosocOncol 12: 33-46. 
Wojtyna, E., Życińska, J., \&Stawiarska, K. (2011): The influence of cognitive-behaviour therapy on quality of life and self-esteem in women suffering from breast cancer, Rep PractOncolRadiother; 12(2): 109-117.

World Health Organization. (2011): Cancer key fact. Fact sheet $\mathrm{N}^{\circ} 297$ February 2011. Available at http://www.who.int/mediacentre/factsheets/fs2 97/en/ Wyrick.

Zigmond, A., \&Snaith, R. (1983): The Hospital Anxiety and Depression Scale. Acta Psychiatr Scand 1983;67:361-70. 